\title{
Neuroendoscopic Septostomy for Isolated Lateral Ventricle
}

\author{
Hideo HAMADA, Nakamasa HAYASHI, Masanori KURIMOTO, Kimiko UMEMURA, \\ Yutaka HIRASHIMA, and Shunro ENDO
}

Department of Neurosurgery, Toyama Medical and Pharmaceutical University, Toyama

\begin{abstract}
The clinical features and endoscopic findings were investigated in 20 patients with isolated lateral ventricle treated by neuroendoscopic septostomy to establish cerebrospinal fluid communication and open an isolated ventricular compartment. The endoscopic procedure was incomplete because of thickened septum pellucidum and insufficient working space in two adults with postmeningitic hydrocephalus. Two children underwent second septostomy. In all other cases, results were good and there were no complications related to endoscopic procedures. Endoscopic septostomy is less invasive and has few complications. Intraoperative navigation and the biportal approach may be required in difficult cases with multiple septum formation and severe postmeningitic hydrocephalus. Adequate stomal size is required in high-risk groups including children under 2 years of age.
\end{abstract}

Key words: hydrocephalus, navigation, neuroendoscopy, septostomy

\section{Introduction}

Secondary hydrocephalus following ventriculitis or intraventricular hemorrhage may be complicated by septum formation in the ventricular system, resulting in complex manifestations of cerebrospinal fluid (CSF) circulation disturbance. Treatment of hydrocephalus with multiple septations and compartments has been difficult and sometimes impossible with the usual methods of shunt placement. Recently, neuroendoscopic third ventriculostomy has been performed to treat patients with obstructive hydrocephalus. Large series have demonstrated the clinical effectiveness of this procedure. Various radical approaches to restore intraventricular circulation of CSF have been used in patients with hydrocephalus associated with intraventricular septal formation, such as fenestration of the septum pellucidum or intraventricular septation, aqueductal plasty, and plasty of the foramen of Monro. ${ }^{2,3,6,7,11-18)}$

The present study evaluated 20 patients who underwent endoscopic septostomy to examine the clinical course and endoscopic findings, and investigate the efficacy and problems associated with endoscopic treatment.

Received February 28, 2003; Accepted June 18, 2003

\section{Patients and Methods}

This retrospective study included 20 patients aged 0 to 83 years, including four children aged 12 years or less, who underwent septostomy with neuroendoscopy for hydrocephalus at our department since January 1996. All patients were followed up for at least 6 months.

The cause of hydrocephalus was classified as follows: Posthemorrhagic hydrocephalus (9 cases), this category included two children, a case with intraventricular hemorrhage (IVH) associated with intracerebral hemorrhage (ICH) and a case with intratumoral hemorrhage originating from primitive neuroectodermal tumor (PNET); postmeningitic hydrocephalus (6 cases); and others.

Septostomy was performed through a standard coronal burr-hole. A peelaway sheath $(14.0 \mathrm{Fr}$; Codman, Inc., Raynham, Mass., U.S.A.) was passed into the anterior horn of the lateral ventricle. A flexible fiberoptic ventriculoscope $(14.0$ Fr.; Codman, Inc.) or a rigid 4-mm-diameter endoscope (Olympus Optical Co., Ltd., Tokyo) was then inserted into the ventricle through the peelaway sheath. We mainly used a flexible fiberscope, because of the need for adequate irrigation of the ventricular system, especially in patients in the acute stage of IVH, and meningitis. Fenestration of the septum pellucidum between the anterior and posterior septal veins was performed with low-current monopolar coagu- 
Table 1 Summary of patients treated by neuroendoscopic septostomy

\begin{tabular}{|c|c|c|c|c|c|c|}
\hline $\begin{array}{l}\text { Case } \\
\text { No. }\end{array}$ & Age & Sex & Primary disease & $\begin{array}{l}\text { Previous } \\
\text { shunt or } \\
\text { drainage }\end{array}$ & Treatment & Result \\
\hline \multicolumn{7}{|c|}{ Isolated lateral ventricle after hemorrhage: } \\
\hline 1 & 56 yrs & $\mathrm{M}$ & $\mathrm{ICH}, \mathrm{IVH}$ & - & $\begin{array}{l}\text { evacuation, } \\
\text { septostomy }\end{array}$ & successful \\
\hline 2 & 83 yrs & $\mathrm{F}$ & ICH, IVH & - & $\begin{array}{l}\text { evacuation, } \\
\text { septostomy }\end{array}$ & successful \\
\hline 3 & 49 yrs & $\mathrm{F}$ & ICH, IVH & - & $\begin{array}{l}\text { evacuation, } \\
\text { septostomy }\end{array}$ & successful \\
\hline 4 & $64 \mathrm{yrs}$ & $\mathrm{M}$ & $\mathrm{ICH}, \mathrm{IVH}$ & - & $\begin{array}{l}\text { evacuation, } \\
\text { septostomy }\end{array}$ & successful \\
\hline 5 & 74 yrs & $\mathrm{M}$ & ICH, IVH & - & $\begin{array}{l}\text { evacuation, } \\
\text { septostomy }\end{array}$ & successful \\
\hline 6 & $65 \mathrm{yrs}$ & $\mathrm{F}$ & $\mathrm{ICH}, \mathrm{IVH}$ & + & $\begin{array}{l}\text { evacuation, } \\
\text { septostomy }+ \text { shunt }\end{array}$ & successful \\
\hline 7 & 50 yrs & $\mathrm{F}$ & $\begin{array}{c}\text { anaplastic astrocytoma with } \\
\text { intratumoral hemorrhage }\end{array}$ & - & septostomy + shunt & successful \\
\hline 8 & $17 \mathrm{mos}$ & $\mathrm{M}$ & $\begin{array}{l}\text { PNET with intratumoral } \\
\text { hemorrhage }\end{array}$ & + & septostomy + shunt & $\begin{array}{l}\text { successful after } \\
\text { reoperation }\end{array}$ \\
\hline 9 & $3 \mathrm{mos}$ & $\mathrm{M}$ & ICH, IVH & - & septostomy + shunt & $\begin{array}{l}\text { successful after } \\
\text { reoperation }\end{array}$ \\
\hline \multicolumn{7}{|c|}{ Isolated lateral ventricle after infection: } \\
\hline 10 & 77 yrs & $\mathrm{F}$ & $\mathrm{SAH}$, meningitis & + & septostomy + shunt & successful \\
\hline 11 & 27 yrs & $\mathrm{F}$ & sepsis, meningitis & - & septostomy + shunt & successful \\
\hline 12 & 50 yrs & $\mathrm{F}$ & SAH, meningitis & + & septostomy & failed \\
\hline 13 & 57 yrs & $\mathrm{F}$ & $\mathrm{SAH}$, meningitis & + & septostomy & failed \\
\hline 14 & 55 yrs & $\mathrm{M}$ & $\begin{array}{l}\text { trauma (CSF rhinorrhea), } \\
\text { meningitis }\end{array}$ & + & septostomy + EVD & successful \\
\hline 15 & 49 yrs & $\mathrm{F}$ & postop ICH, meningitis & + & septostomy + EVD & successful \\
\hline \multicolumn{7}{|l|}{ Others: } \\
\hline 16 & 48 yrs & $\mathrm{F}$ & sarcoidosis & + & septostomy + shunt & successful \\
\hline 17 & 20 yrs & $\mathrm{M}$ & $\begin{array}{l}\text { postop trauma, } \\
\text { septal formation }\end{array}$ & - & septostomy & successful \\
\hline 18 & $41 \mathrm{yrs}$ & $\mathrm{F}$ & $\begin{array}{l}\text { postop AVM, } \\
\text { septal formation }\end{array}$ & - & septostomy + shunt & successful \\
\hline 19 & 4 yrs & $\mathrm{F}$ & MMC, shunt malfunction & + & septostomy + shunt & successful \\
\hline 20 & $12 \mathrm{yrs}$ & $\mathrm{M}$ & $\begin{array}{l}\text { aqueductal stenosis, } \\
\text { post-ETV hemorrhage }\end{array}$ & - & septostomy & successful \\
\hline
\end{tabular}

AVM: arteriovenous malformation, CSF: cerebrospinal fluid, ETV: endoscopic third ventriculostomy, EVD: external ventricular drainage, ICH: intracerebral hemorrhage, IVH: intraventricular hemorrhage, MMC: myelomeningocele, PNET: primitive neuroectodermal tumor, postop: postoperative, SAH: subarachnoid hemorrhage.

lation to form a stoma with a diameter of at least $10 \mathrm{~mm}$.

Endoscopic septostomy was emergently performed for the treatment of unilateral hydrocephalus and endoscopic evacuation of hematoma in patients with IVH associated with ICH causing obstruction of the foramen of Monro. This procedure allowed both removal of ICH, but also evacuation of IVH and resolution of the pathogenesis of the isolated lateral ventricle. ${ }^{8)}$

A navigation system (Evans; Tomiki Medical Instrument Co., Ltd., Kanazawa) was used to establish the intraoperative orientation in cases with multiple septum formation and to tap the anterior horn of the lateral ventricle accurately in cases with slit-like ventricle. This navigation system can monitor the position of the tip of a rigid endoscope. This system was used in Cases 8 and 16.

\section{Results}

The clinical features and outcomes of the patients are summarized in Table 1.

Septostomy was not completely successful in two patients with isolated lateral ventricle with postmeningitic hydrocephalus (Cases 12 and 13), because the septum and ependyma were very thick due to severe inflammation, and sufficient working 


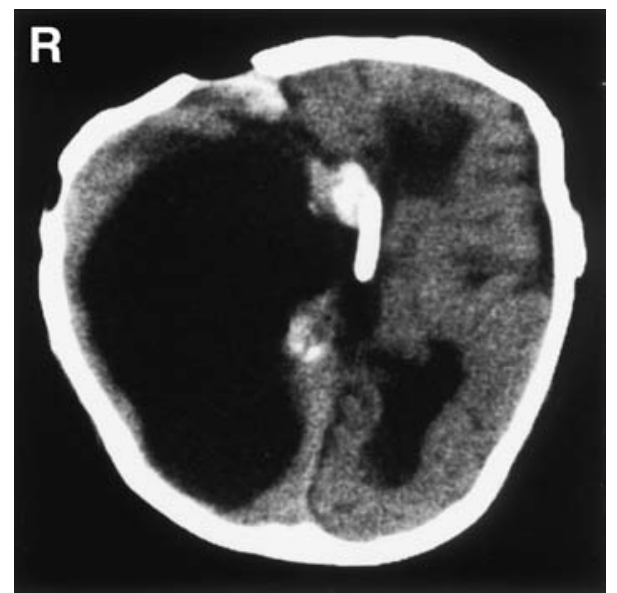

Fig. 1 Case 8. Computed tomography scan disclosing an isolated lateral ventricle.

space could not be obtained due to decreased ventricular elasticity. Marked ventriculitis was one of the characteristic endoscopic findings in Cases 11-13.

Follow-up computed tomography (CT) showed unilateral reaccumulation of CSF in the lateral ventricle in two pediatric patients (Cases 8 and 9), necessitating second endoscopic septostomy, which achieved good communication with the ventricular system. Follow-up CT showed that the lateral ventricles were symmetrical after septostomy.

Septostomy and adequate evacuation of the hematoma were performed in all six patients with obstruction of the foramen of Monro after IVH associated with ICH, using an endoscope introduced through the stoma of the septum pellucidum from the contralateral anterior horn. ${ }^{8)}$ Good results were obtained during the follow-up period and there were no complications of endoscopic procedures in all cases.

\section{Illustrative Cases}

Case 8: A 17-month-old boy had ventriculomegaly in utero, and underwent normal vaginal delivery. He suffered partial seizures on the first day of life. CT revealed bilateral ICH in the frontal lobes, IVH, and marked hydrocephalus. The hematoma was removed. The histological diagnosis was PNET. Repeat CT disclosed progressive unilateral hydrocephalus, so septostomy with ventriculoperitoneal (VP) shunt was attempted, but failed due to poor surgical orientation. A VP shunt was subsequently placed through the bilateral anterior horns with a Y-shaped connector. Three months after VP shunt placement, he presented with complaints of irrita-

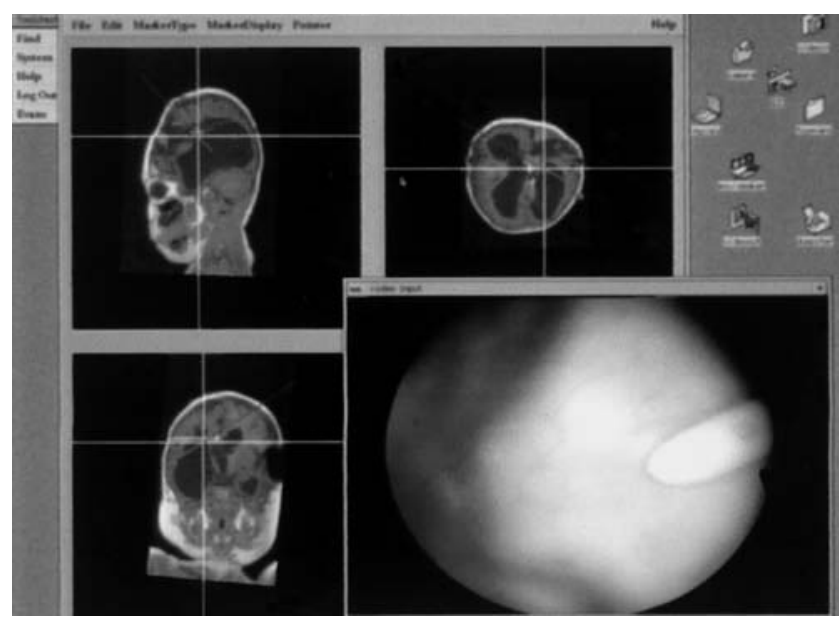

Fig. 2 Case 8. Intraoperative view of the navigation system guidance.

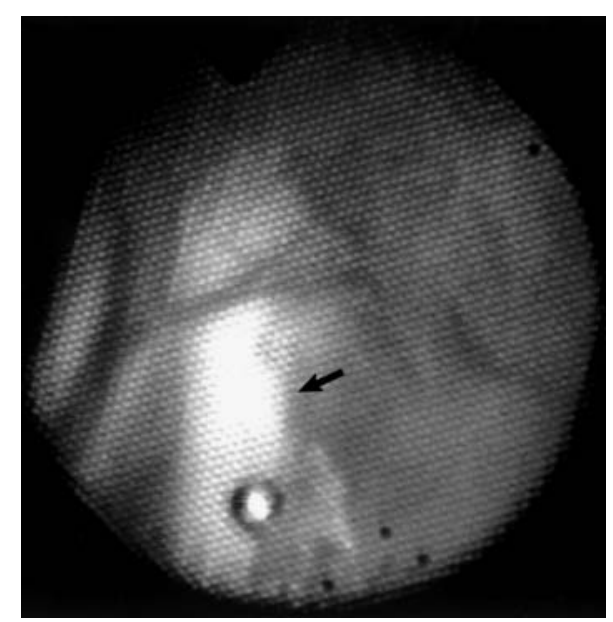

Fig. 3 Case 8. Endoscopic view showing the stoma which was completely occluded by thin membranous tissue. arrow: Shunt tube in the contralateral ventricle.

bility and frequent vomiting.

CT and ventriculography disclosed an isolated lateral ventricle (Fig. 1), so endoscopic septostomy was performed with navigation system guidance (Fig. 2) and obtained good results. Six months after the first endoscopic septostomy, he again presented with the complaints of irritability and frequent vomiting. Repeat CT revealed an isolated lateral ventricle. Second endoscopic septostomy observed a stoma completely occluded by thin membranous tissue (Fig. 3). Fenestration of the membranous tissue and dilation of the stoma to about $10 \mathrm{~mm}$ in diameter was performed. Symmetrical reduction of 


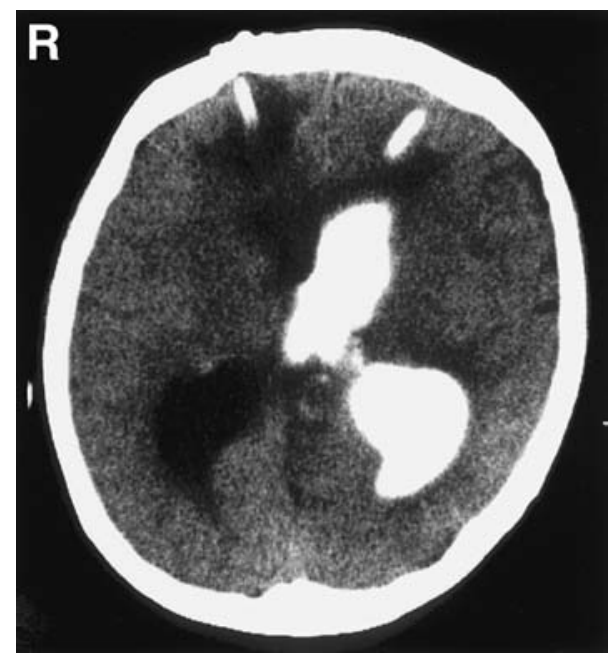

Fig. 4 Case 11. Computed tomography scan revealing an isolated lateral ventricle.

the size of the lateral ventricle was observed after the second septostomy.

Case 11: A 27-year-old female suffered from ulcerative colitis and was treated with prednisolone. She complained of fever and headache at another hospital. The diagnosis was bacterial meningitis based on CSF study. She gradually developed disturbance of consciousness. CT disclosed hydrocephalus. External ventricular drainage was begun. However, repeat CT revealed an isolated lateral ventricle, and she was transferred to our hospital for insertion of bilateral external ventricular drainages.

CT and ventriculography disclosed an isolated lateral ventricle (Fig. 4). Endoscopic septostomy was first attempted from the left anterior horn, but accurate orientation was not possible because of thickened ependyma following severe inflammation covering the normal ventricular wall. Normal anatomical structures, including the foramen of Monro, the septal vein, and the choroid plexus in the left anterior horn, could not be identified. Therefore, biportal methods, approaching from both sides of lateral ventricles, were used. The endoscope was inserted from the right anterior horn with careful anatomical inspection. The ependyma was also thickened in the right anterior horn, but the anterior septal vein and the thalamostriate vein could be detected (Fig. 5). Fenestration of the septum pellucidum behind the anterior septal vein was performed with low-current monopolar coagulator. Since the septum pellucidum was also thickened and multilayered, each layer was we carefully fenestrated before entering the contralateral ventricle. The VP
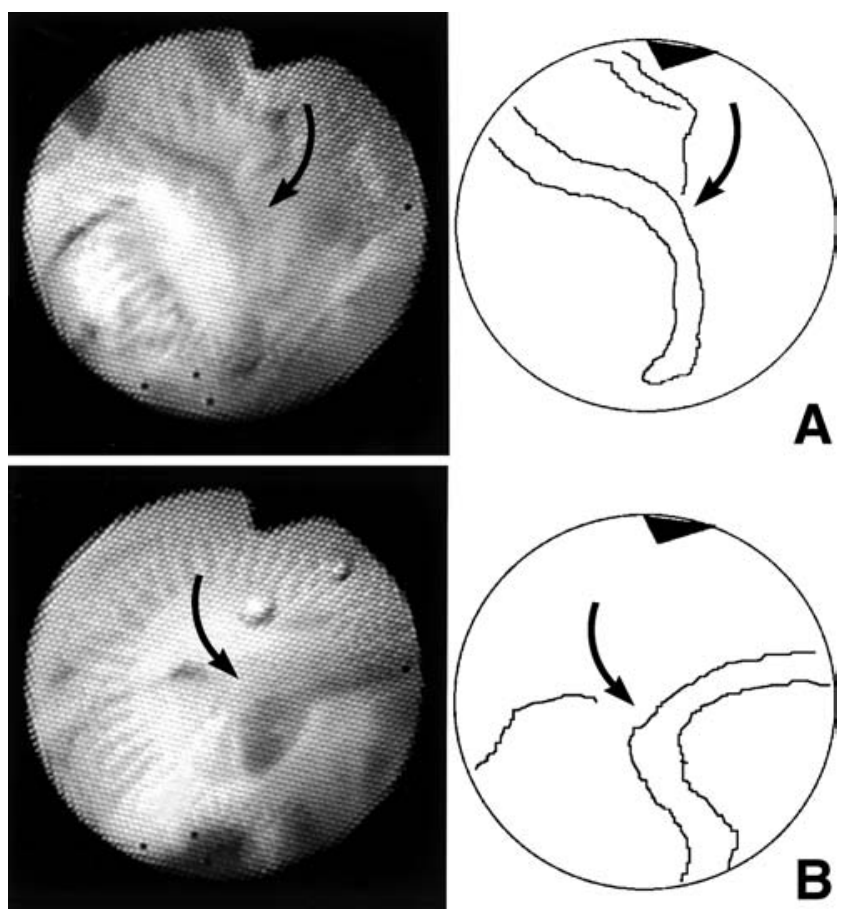

Fig. 5 Case 11. Endoscopic views disclosing thickened ependyma covering the anterior septal vein (A, arrow) and the thalamostriate vein $(B$, arrow).

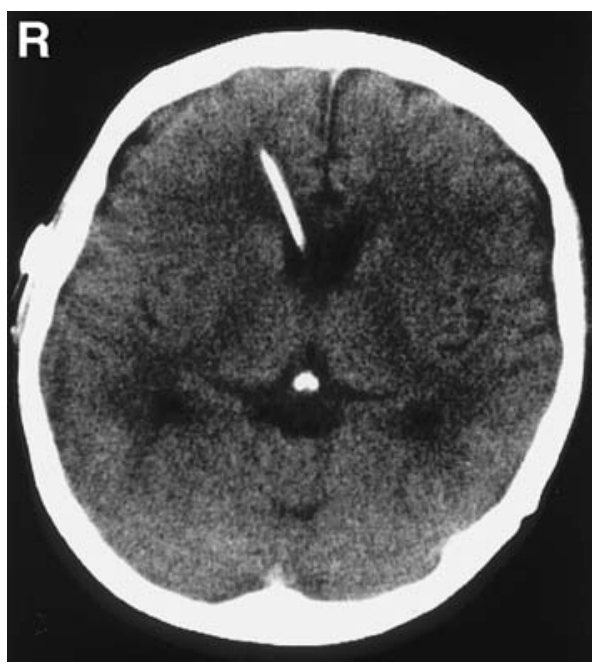

Fig. 6 Case 11. Follow-up computed tomography scan after ventriculoperitoneal shunting following septostomy revealing symmetrical reduction in size of the lateral ventricles.

shunt was inserted after endoscopic septostomy. Symmetrical reduction in size of the lateral ventricles was observed (Fig. 6). She was asymptomatic at the 2-year follow-up examination. 


\section{Discussion}

Loculation of the lateral ventricular system and isolation of the fourth ventricle can occur following IVH. ${ }^{5)}$ Ependymal flaps or chronic inflammation, with formation of membranes, can cause such loculation of the lateral ventricle. Overdrainage is also thought to be a cause of isolated ventricles after shunting, such as isolated fourth ventricle and isolated lateral ventricle. ${ }^{10,16)}$ In our series, hemorrhage and meningitis including ventriculitis were the main causes of this disorder.

Isolated lateral ventricle is often treated by septostomy with placement of an additional shunt, fenestration of the septum pellucidum, or foraminal plasty. Additional shunt placement has been the conventional method for treatment of this condition. However, multiple shunt placement is complicated and often results in shunt malfunction. Therefore, we performed neuroendoscopic septostomy to simplify the pathogenesis of inoperable hydrocephalus. Septostomy helps to restore the intraventricular circulation of the CSF and opens the isolated ventricular compartments, reducing the requirement for multiple shunt systems.

Our series of 20 patients who underwent endoscopic septostomy obtained good outcomes at long-term follow-up examination, except for two patients with severe meningitis in whom septostomy was impossible because of intraventricular multiple septum formation, thickened septum pellucidum, and insufficient working space due to severe inflammation. However, we managed to perform septostomy using a biportal approach and obtained good results in a patient with thickened and multilayer septum pellucidum after severe meningitis and ventriculitis. Simultaneous approaches from the bilateral anterior horns, guiding the endoscope on one side with a light, and intraoperative navigation were helpful for determining the point of fenestration of the thickened septum pellucidum. Effective septostomy can be performed using such methods.

Endoscopic third ventriculostomy has a lower rate of success for patients with posthemorrhagic or postmeningitic hydrocephalus, or myelomeningocele. ${ }^{4)}$ Third ventriculostomy carries greater risk of postoperative stomal obstruction in patients aged under 2 years with hydrocephalus accompanied by IVH and associated with meningocele. ${ }^{9}$ The success rate is lower in patients aged under 2 years. ${ }^{1)}$ Since two of three children required reoperation because of occlusion of the stoma in our series, we suggest that endoscopic septostomy involves the risk of occlusion in children, especially in those under 2 years of age. We assume that occlusion of the stoma due to active proliferation of cells in ependymal layers under 2 years of age. However, the risk can be reduced by making a sufficiently large stoma. Moreover, stent placement may be useful in these cases. We successfully performed endoscopic aqueductal plasty using a stent in children with isolated fourth ventricle and obtained good outcomes without reoperation. ${ }^{7,9)}$ Therefore, we propose that endoscopic septostomy should be chosen as the initial treatment. In addition, efforts to reduce the causes of this pathology are necessary.

Endoscopic septostomy is safe and less invasive, and results in few complications. Intraoperative navigation and the biportal approach are helpful in establishing the intraoperative orientation in difficult cases with multiple septum formation and severe postmeningitic hydrocephalus. The stoma should be at least $10 \mathrm{~mm}$ in diameter in high-risk cases with postoperative obstruction, such as children under 2 years of age.

\section{References}

1) Barow P: Indication for endoscopic third ventriculostomy: A review of successful and failed cases. Br J Neurosurg 11: 456, 1997

2) Birnholz JC: Septum pellucidum fenestration: visualization by ultrasound. Radiology 149: 122, 1983

3) Boylar B, Ildan F, Bagdatouglu H, Cetinalp E, Karadayi A: Unilateral hydrocephalus resulting from occlusion of foramen of Monro: a new procedure in the treatment: stereotactic fenestration of the septum pellucidum. Surg Neurol 39: 110-114, 1993

4) Buxton N, Macarthur D, Mallucci C, Punt J, Vloeberghs M: Neuroendoscopic third ventriculostomy in patients less than 1 year old. Pediatr Neurosurg 29: 73-76, 1998

5) Eller TW, Pasternak JF: Isolated ventricles following intraventricular hemorrhage. J Neurosurg 62: 357-362, 1985

6) Gangemi M, Maiuri F, Donati PA, Signorelli F, Basile D: Endoscopic surgery for monoventricular hydrocephalus. Surg Neurol 52: 246-251, 1999

7) Hamada H, Hayashi N, Endo S, Kurimoto $M$, Hirashima Y, Takaku A: Endoscopic aqueductal plasty via the fourth ventricle through the cerebellar hemisphere under navigating system guidance. Technical note. Neurol Med Chir (Tokyo) 39: 950-954, 1999

8) Hayashi N, Endo S, Hamada H, Umemura K, Takaku A, Horie Y: [Endoscopic evacuation of thalamic hemorrhage associated with intraventricular hemorrhage]. Surgery for Cerebral Stroke 27: 110-114, 1999 (Jpn)

9) Hayashi N, Hamada H, Hirashima Y, Kurimoto M, Takaku A, Endo S: Clinical features in patients requiring reoperation after failed endoscopic procedures for hydrocephalus. Minim Invasive Neurosurg 43: 181-186, 2000 
10) Hayashi $T$, Hashimoto $T$, Fukuda $S$, Anegawa $S$, Torigoe R: [Clinical analysis of shunted hydrocephalic neonates and sucklings. Observation of postshunt complication due to overdrainage from intraventricular CSF]. No To Shinkei 42: 1167-1171, 1990 (Jpn, with Eng abstract)

11) Heilman CB, Cohen AR: Endoscopic ventricular fenestration using a "saline torch." J Neurosurg 74: 224-229, 1991

12) Jamjoom AB, Mohamed AA, Al-Boukai A, Jamjoom ZA, Rahman N, Jamjoom HT: Multiloculated hydrocephalus related to cerebrospinal fluid shunt infection. Acta Neurochir (Wien) 138: 714-719, 1996

13) Kehler U, Gliemroth J, Arnold H: Asymmetric hydrocephalus: safe endoscopic perforation of septum pellucidum: technical note. Minim Invasive Neurosurg 40: 101-102, 1997

14) Lewis AL, Keiper GL, Crone KL: Endoscopic treatment of loculated hydrocephalus. J Neurosurg 82: 780-785, 1995

15) Mohanty A, Das BS, Sastry Kolluri VR, Hedge T: Neuro-endoscopic fenestration of occluded foramen of Monro causing unilateral hydrocephalus. Pediatr
Neurosurg 25: 248-251, 1996

16) Oi S, Hidaka M, Honda $Y$, Togo K, Shinoda M, Shimoda M, Tsugane R, Sato O: Neuroendoscopic surgery for specific forms of hydrocephalus. Childs Nerv Syst 15: 56-68, 1999

17) Oi S, Matsumoto S: Pathophysiology of nonneoplastic obstruction of the foramen of Monro and progressive unilateral hydrocephalus. Neurosurgery 17: 891-896, 1985

18) Wong TT, Lee LS: Membranous occlusion of the foramen of Monro following ventriculoperitoneal shunt insertion: a role for endoscopic foraminoplasty. Childs Nerv Syst 16: 213-217, 2000

Address reprint requests to: H. Hamada, M.D., Department of Neurosurgery, Toyama Medical and Pharmaceutical University, 2630 Sugitani, Toyama 930-0194, Japan.

e-mail: hideo@ms.toyama-mpu.ac.jp

Commentary on this paper appears on the next page. 


\section{Commentary}

Hamada et al. report their experience in 20 patients who underwent neuroendoscopic fenestration of the ventricular system to achieve a cerebrospinal fluid communication in patients with loculated ventricles. They report their usage of either a single channel or a two channel (bifrontal) neuroendoscopic approach, most commonly using a flexible fiberoptic endoscope. Using this approach, primarily for post-hemorrhagic or post-meningitic hydrocephalus, they provided successful communication in most patients. This facilitated unilateral ventricular peritoneal shunt placement in some patients who otherwise required bi-ventricular shunts. The technique was applied to children as young as three months, and patients as old as 83 years. The complication rate was remarkably low, and the diversity of applications was remarkably high.

Minimally invasive techniques are being increasingly applied in the neurosurgical operating room to diagnose and to treat a wide variety of intracranial cystic lesions, those with unilaterally loculated ventricles, and in some patients with ventricular ependymal cysts. Historically, usage of the endoscope was pioneered in the 1940s using the then available rigid ureteroscopes, with work being done by a number of investigators at the New York Neurological Institute, including John Scarff. The technique fell into disregard for many years, only to be prodded back into existence in the traditional 25 year cycle of neurosurgery. At that time, new flexible, and smaller working channel endoscopes were developed and optics dramatically improved.

These new endoscopes permitted rapid clearing of the spinal fluid pathways, as even a small amount of blood can lead to a view through the endoscope that looks like "driving in a snow storm with your high beams on" (attributed to Bennett Stein, M.D.).

Our group has used neuroendoscopy for third ventriculostomy and pituitary tumor resection. More recently, we used precise stereotactic guidance to place a small "ventriculoport" into the ventricular system. Through the port, a rigid endoscope could be used as a visualization tool. We use an 11-mm channel and standard microsurgical instruments to resect intraventricular tumors and colloid cysts. ${ }^{2)}$ The technique of using stereotactic guidance facilitates placement of the "ventriculoport." Similarly, image-guided techniques can be used to place such tube conduits to facilitate resection of deep seated intracranial tumors using neuroendoscopy assisted microsurgery. Interestingly, such endoscopy techniques may be able to be used to place stents to keep the stoma open longer, a technique first suggested by Leksell in the 1940s and confirmed by Backlund during the 1970s. ${ }^{1)}$

Neurosurgical training programs must teach our current generation of residents the art and value of endoscopically assisted tumor removal, cyst fenestration, and clot removal.

\section{References}

1) Backlund EO, Grepe A, Lunsford LD: Stereotactic reconstruction of the aqueduct of Sylvius. J Neurosurg 55: 800-810, 1981

2) Harris AE, Hadjipanayis CG, Lunsford LD, Lunsford AK, Kassam A: Endoscopic removal of intraventricular lesions assisted by stereotactic CT-guidance. Neurosurgery 2003 (submitted)

L. Dade Lunsford, M.D. Department of Neurological Surgery University of Pittsburgh Medical Center Pittsburgh, Pennsylvania, U.S.A.

Neuroendoscopic surgery has enabled us to improve the clinical results of surgical treatment of various complicated hydrocephalic entities, which have been so far difficult to treat. The authors investigated the clinical and endoscopic features of 20 patients with isolated lateral ventricle treated by endoscopic septostomy. On the basis of their results, they evaluated the efficacy and substantiated problems of this newly developed strategy in the treatment of hydrocephalus with septations and compartments caused by various etiologies. They have also proposed the use of intraoperative navigation and the biportal approach in difficult cases with multiple septum formation and severe postmeningitic hydrocephalus which might help to improve the clinical outcome of treatment. They also stressed the adequateness of the stomal size or the use of stent in septostomy in high risk groups including children under 2 years of age. Although a longer follow up and an increase in number of cases are advisable, this paper encourages us in the treatment of intractable hydrocephalus.

Kouzo Moritake, M.D.

Department of Neurosurgery

Shimane University School of Medicine Izumo, Shimane, Japan 